\title{
AVALIAÇÃO FÍSICO-QUÍMICA E MICROBIOLÓGICA DA AMÊNDOA DA CASTANHA DE CAJU
}

\section{PHYSICOCHEMICAL AND MICROBIOLOGICAL EVALUATION OF ALMOND CASHEW NUT}

\author{
Jose Maria Correia Costa ${ }^{1}$, Kelen Tostes Guerra ${ }^{2}$, Geraldo Arraes Maia ${ }^{3}$, \\ Érica Milô Freitas Felipe Rocha ${ }^{4}$ \\ ${ }^{1}$ Universidade Federal do Ceará. E-mail: correia@ufc.br, \\ ${ }^{2}$ Universidade Federal do Ceará E-mail: kelen_tostes13@homail.com \\ ${ }^{3}$ Universidade Federal do Ceará, Centro de Ciências Agrárias, Departamento de \\ Tecnologia de Alimentos. E-mail: gmaia@ secrel.com.br, \\ ${ }^{4}$ Universidade Federal do Ceará. E-mail: ericamff@yahoo.com.br
}

Recebido para publicação em: 14/04/2009

Aceito para publicação em: 01/12/2009

\begin{abstract}
RESUMO
A amêndoa da castanha de caju é um importante agronegócio e produto de expressão econômica para o Brasil. Tendo em vista essa grande importância, foram utilizadas amostras de amêndoas inteiras de castanha de caju crua tipo LW1 e castanha de caju torrada e salgada tipo W4TS para avaliar as características físico-químicas de lipídeos, acidez titulável, umidade, índice de peróxidos, teor de ranço, e as características microbiológicas, através das análises de Salmonella ssp e Coliformes Total e Fecal. Os resultados médios observados nas análises físico-químicas para as amêndoas cruas e as amêndoas torradas e salgadas foram, respectivamente: lipídios $(45,43 \mathrm{~g} / 100 \mathrm{~mL}$ e $45,68 \mathrm{~g} / 100 \mathrm{~mL})$, umidade $(3,70 \% \mathrm{e}$ $2,25 \%$ ), Índice de peróxido (1,03 e 2,13 mEq/ Kg) e Acidez (0,56 e 0,74 \%). Em relação aos parâmetros microbiológicos, as amostras analisadas apresentavam-se dentro dos parâmetros exigidos pela legislação vigente. Com este trabalho pode ser observado que, durante o período de validade (12 meses) estabelecido pela indústria fornecedora da matéria-prima, tanto as amêndoas da castanha de caju crua tipo LW1 quanto às amêndoas da castanha de caju torrada e salgada tipo W4TS não apresentaram redução em sua qualidade final.
\end{abstract}

Palavras-chave: Anacardium ocidentale. Fruto. Qualidade. Estabilidade.

\begin{abstract}
The almond cashew nut is an important product of agribusiness and economic expression for Brazil. Given this importance, samples of whole kernels of raw cashew nut type LW1 and cashew nuts and roasted salted kind W4TS to


evaluate the physico-chemical properties of lipids, acidity, moisture, peroxide value, content rancidity and, through microbiological analysis of Salmonella ssp and Total and Fecal Coliforms. The average results observed on the physicalchemical for the raw almonds and roasted and salted almonds were, respectively: lipids $(45.43 \mathrm{~g} / 100 \mathrm{~mL}$ and $45.68 \mathrm{~g} / 100 \mathrm{~mL})$, moisture $(3.70 \%$ and $2.25 \%)$, peroxide (1.03 and $2.13 \mathrm{mEq} / \mathrm{kg}$ ) and acidity $(0.56$ and $0.74 \%)$. With regard to microbiological parameters, the samples had to be within the parameters required by law. This work can be seen that during the validity period (12 months) fixed by the industry supplier of raw material, both the kernels of raw cashew nuts LW1 kind as to the cashew nuts and roasted salted kind W4TS not showed a reduction in their final quality.

Keywords: Anacardium ocidentale. Fruit. Quality. Stability.

\section{INTRODUÇÃO}

A castanha de caju é o verdadeiro fruto do cajueiro (Anacardium occidentale L.), explorado comercialmente nos continentes Asiático, Africano e Sul-Americano. Destacam-se, como os principais exportadores da amêndoa de castanha de caju (ACC), a Índia, o Vietnã e o Brasil. As castanhas apresentam tamanho variável, cor cinza-amarronzada, epicarpo liso, mesocarpo alveolado contendo o líquido escuro, caústico e inflamável, denominado líquido da castanha de caju - LCC (ARAÚJO; FERRAZ, 2006).

$\mathrm{O}$ produto de maior expressão econômica do cajueiro é a amêndoa, parte comestível da castanha, que representa em média $30 \%$ de seu peso. A amêndoa da castanha de caju torrada e salgada constitui a principal forma de consumo, sendo usada no acompanhamento de coquetéis e bebidas. A amêndoa torrada sem sal serve para a confecção de bolos, doces, bombons e chocolates, enriquecendo-lhes o sabor e aspecto (ARAÚJO; FERRAZ, 2006).

No Brasil, a agroindústria do caju está concentrada no Nordeste, tendo apresentado em 2008 uma produção anual de 243.253 toneladas, sendo que os Estados do Ceará, Piauí e Rio Grande do Norte participam com $90 \%$ dessa produção (IBGE, 2010). O parque industrial é composto por 12 empresas ( 08 no estado do Ceará, 03 no Rio Grande do Norte e 01 no estado do Piauí), onde são processadas, anualmente, até 360 mil toneladas de castanha, gerando 70 mil toneladas de ACC - amêndoa de castanha de caju e 45 mil toneladas de LCC - líquido da casca da castanha (TEIXEIRA, 2007). O Ceará representa 50\% da área cultivada de caju no país, sendo responsável pela geração de 30 mil empregos diretos e cem mil empregos indiretos. Além disso, confere uma importância social à agroindústria do caju, devido a sua capacidade de geração de empregos na entressafra de outras atividades agropecuárias (FIEC, 2007; FRANÇA et al., 2008).

As operações envolvidas no processamento de amêndoas de castanha de caju são basicamente o cozimento, a secagem, o corte, a decorticação, a despeliculagem, a classificação, a fritura, no caso das amêndoas torradas, e a embalagem (LIMA; SOUSA, 2001). Essas amêndoas de castanha de caju processadas possuem alto teor de gordura e baixo teor de umidade, características que fazem com que esses produtos sejam suscetíveis ao ganho de umidade, com consequente possibilidade de perda de textura, degradação microbiológica e oxidação (LIMA; BORGES, 2004).

As características físico-químicas que estão presentes no fruto podem variar segundo o cultivo e as condições ambientais da região (BARCELÓ COLL et al., 2005; STENZEL et al., 2006). Segundo Matta et al. (2004), a preservação das características originais dos alimentos pelo maior tempo possível, após sua transformação, é um dos grandes objetivos da indústria de alimentos; e as condições do ambiente e do armazenamento (tais como a temperatura, umidade e luminosidade), bem como o tipo de embalagem utilizada são aspectos que devem ser analisados e controlados, visando à manutenção da qualidade dos produtos durante a vida de prateleira.

Tendo em vista a elevada importância econômica, a necessidade de melhor caracterização da matéria-prima existente e as influências que os tipos 
de embalagem podem trazer ao produto, o presente trabalho teve por objetivo verificar a qualidade e/ ou estabilidade da amêndoa da castanha do caju crua e da amêndoa tostada e salgada, buscando identificar as alterações ocorridas nesse produto durante seu processo de armazenamento.

\section{MATERIAL E MÉTODOS}

\subsection{Amostragem}

Foram utilizadas duas amostras de amêndoas da castanha de caju: a inteira e crua, classificada como tipo LW1, e a brocada, torrada e salgada, denominada tipo W4TS, procedente de uma indústria de beneficiamento de castanha de caju da cidade de Fortaleza - Ceará.

De cada amostra foram adquiridas, em embalagem comercial, 12 caixas em papelão ondulado, que continham 24 sacos metalizados com estrutura em polipropileno biorientado com 11,34 kg/cada e 24 latas litografadas em aço estanhado com $11,34 \mathrm{~kg} / \mathrm{cada}$ para as amêndoas tipo LW1 e W4TS, respectivamente. Essas amostras foram armazenadas pelo período de 12 meses, prazo de validade estabelecido pela indústria fornecedora da matéria-prima, procedendo-se as análises físico-químicas e microbiológicas a cada mês (30 dias).

\subsection{Determinações físico-químicas e mi- crobiológicas}

As determinações físico-químicas, em duplicata, das amêndoas de castanha de caju foram efetuadas no Laboratório de Controle de Qualidade e Secagem do Departamento de Tecnologia em Alimentos da Universidade Federal do Ceará e no Laboratório do NUTEC. Os teores de lipídeos com resultados expressos em percentual do peso da amostra seca, a acidez titulável pela titulação com hidróxido de sódio $0,1 \mathrm{~N}$ e resultados expressos em g de ácido oléico/ $100 \mathrm{~g}$, a umidade determinada utilizando-se estufa à $102^{\circ} \mathrm{C}$ até peso constante, o índice de peróxido e o teor de ranço determinado pela reação de Kreiss seguiram as normas do Instituto Adolfo Lutz (2004).

As determinações microbiológicas realizadas foram: a análise de Salmonella spp. segundo o método da APHA (1992), e de Coliformes Total e Fecal segundo metodologia da A.O.A.C (1995).

Os resultados médios das análises físico-químicas das amêndoas de castanha de caju crua e amêndoas de castanha de caju brocada, torrada e salgada foram tratados estatisticamente através da Análise de Variância (ANOVA) e foi também aplicado o teste de Tukey entre as médias a $5 \%$ de probabilidade. Tais resultados foram avaliados pelo programa SAEG (UFV) versão 8.1 (2003).

\section{CASTANHA DE CAJU}

- Recebimento da Matéria-Prima

- Secagem (Redução da umidade $=<9 \%$ )

- Pré-limpeza (Retirada de Impurezas)

- Classificação por Tamanho

- Umidificação

- Cozimento $\left(\mathrm{T}=200-225^{\circ} \mathrm{C}\right)$

- Centrifugação e Resfriamento

- Decorticadores (Retirada da Casca)

- Estufagem e Despeliculamento

- Seleção/Classificação/ Revisão (Retirada de defeitos)

- Embalagem (sacos aluminizados acondicionadas em caixas de papelão ondulado)

- Armazenament0o da Amêndoa Crua Tipo LW1

\section{AMÊNDOA CRUA}

- Torrefação $\left(\mathrm{T}=170+10{ }^{\circ} \mathrm{C}\right)$

- Centrifugação e Resfriamento

- Seleção (Retirada de Defeitos)

- Salga (adição de 2\%)

- Embalagem (Latas litografadas em aço estanhado)

- Armazenamento da Amêndoa brocada torrada e salgada Tipo W4TS

Figura 1 - Esquema de obtenção das amêndoas cruas tipo LW1 e amêndoas brocadas torradas e salgadas tipo W4TS. 


\section{RESULTADOS E DISCUSSÃO}

Na Tabela 1, podem ser observados os resultados obtidos para o parâmetro de lipídeo, no período de 12 meses, das amêndoas de castanha de caju crua LW1 e amêndoas de castanha de caju torrada e salgada W4TS.

Tabela 1 - Teores de lipídeos nas amêndoas cruas e nas amêndoas torradas e salgadas

\begin{tabular}{c|c|c}
\hline \multirow{2}{*}{ Estocagem (mês) } & \multicolumn{2}{|c}{ Lipídeo (g/100mL) } \\
\cline { 2 - 3 } & $\begin{array}{c}\text { Amêndoa crua } \\
\text { LW1 }\end{array}$ & $\begin{array}{c}\text { Amêndoa torrada } \\
\text { e salgada W4TS }\end{array}$ \\
\hline 01 & 45,00 & 45,00 \\
\hline 02 & 45,50 & 45,50 \\
\hline 03 & 45,00 & 44,50 \\
\hline 04 & 45,00 & 46,00 \\
\hline 05 & 46,50 & 46,50 \\
\hline 06 & 47,50 & 47,00 \\
\hline 07 & 45,67 & 48,00 \\
\hline 08 & 45,00 & 44,33 \\
\hline 09 & 45,00 & 44,00 \\
\hline 10 & 43,33 & 44,67 \\
\hline 11 & 45,33 & 46,33 \\
\hline 12 & 46,33 & 46,33 \\
\hline Média \pm Desvio & $\mathbf{4 5 , 4 3} \pm \mathbf{1 , 0 3}$ & $\mathbf{4 5 , 6 8} \pm \mathbf{1 , 2 2}$ \\
\hline Padrão & &
\end{tabular}

Nota: Valores médios numa mesma linha com letras minúsculas e iguais não diferem significativamente entre si a $5 \%$ de probabilidade, segundo o Teste de Tukey.

Como se pode observar na Tabela 1 , os valores de lipídeos variam de 43,33 a 48,00 g/100mL com teores médios de $45,43 \mathrm{~g} / 100 \mathrm{~mL}$ e $45,68 \mathrm{~g} / 100 \mathrm{~mL}$ para as amêndoas cruas e as amêndoas tostadas e salgadas, respectivamente. Esses resultados mostraram concordância com os valores observados por Cavalcante (1983), que apresentou 44,52\% no teor de lipídeo para as amêndoas cruas e 57,20\% para as amêndoas tostadas, enquanto que Andrade (1984), em seu estudo sobre os aspectos da industrialização da castanha de caju, observou uma diferença bem inferior entre os dois tipos de amêndoas, com valores de 45,30\% e 45,71\% para as amêndoas cruas e tostadas, respectivamente. Segundo Maia e Stull (1977), as castanhas de caju do Brasil apresentam valores aproximados de lipídeos de 45,6\%. O valor de lipídeo para amêndoas cruas foi ainda comparável ao relatado por Melo (1998), que foi de 46,5\%. Entretanto, resultados inferiores $(42,25 \%)$ foram observados por Queiroga Neto (1993).

Comparando-se os valores médios obtidos do parâmetro de lipídeo para as amêndoas cruas e as amêndoas tostadas e salgadas, não se constatou nenhuma dif,erença significativa em nível de 5\% de probabilidade, resultado não esperado, pois as amêndoas tostadas e salgadas deveriam ter apresentado maiores teores devido ao processo de torrefação realizado através da imersão dessas amêndoas em gordura hidrogenada de algodão.

Quanto aos valores de acidez titulável, apresentados na Tabela 2, observou-se teores médios de $0,56 \mathrm{~g} / 100 \mathrm{~mL}$ e $0,74 \mathrm{~g} / 100 \mathrm{~mL}$ para as amêndoas cruas e as amêndoas tostadas e salgadas, respectivamente, apresentando diferença significativa ao nível de 5\% de probabilidade. Tais resultados estão em concordância com Melo et al. (1998) em sua pesquisa sobre a caracterização físico-química da amêndoa da castanha de caju (Anacardium occidentale L.) crua e tostada, pois os referidos autores observaram diferença significativa entre as amostras analisadas e afirmaram que essa diferença pode ser consequência do processo de torrefação.

Tabela 2 - Teores de acidez titulável nas amêndoas cruas e nas amêndoas torradas e salgadas

\begin{tabular}{|c|c|c|}
\hline \multirow[b]{2}{*}{ Estocagem (mês) } & \multicolumn{2}{|c|}{ Acidez titulável $(\mathrm{g} / 100 \mathrm{~mL})$} \\
\hline & $\begin{array}{c}\text { Amêndoa crua } \\
\text { LW1 }\end{array}$ & $\begin{array}{c}\text { Amêndoa torrada } \\
\text { e salgada W4TS }\end{array}$ \\
\hline 01 & 0,74 & 0,75 \\
\hline 02 & 0,40 & 0,48 \\
\hline 03 & 0,60 & 0,73 \\
\hline 04 & 0,40 & 0,73 \\
\hline 05 & 0,48 & 0,75 \\
\hline 06 & 0,50 & 0,72 \\
\hline 07 & 0,61 & 0,84 \\
\hline 08 & 0,42 & 0,84 \\
\hline 09 & 0,41 & 0,81 \\
\hline 10 & 0,82 & 0,84 \\
\hline 11 & 0,87 & 0,78 \\
\hline 12 & 0,45 & 0,61 \\
\hline $\begin{array}{c}\text { Média } \pm \text { Desvio } \\
\text { Padrão }\end{array}$ & $\mathbf{0 , 5 6} 6^{\mathrm{b}} \pm \mathbf{0 , 1 7}$ & $0,74^{\mathrm{a}} \pm \mathbf{0 , 1 0}$ \\
\hline
\end{tabular}

Nota: Valores médios numa mesma linha com letras minúsculas e iguais não diferem significativamente entre si a $5 \%$ de probabilidade, segundo o Teste de Tukey. 
O índice de acidez está intimamente relacionado com a natureza e a qualidade da matéria-prima, com a qualidade e o grau de pureza da gordura, com o processamento e, principalmente, com as condições de conservação da gordura (MORETTO; FETT, 1998). Logo, os resultados encontrados estão satisfatórios, uma vez que não foram obtidos teores altos de acidez durante o armazenamento. Souza et al. (1986) citam que o máximo calculado para acidez em amêndoa é 2,0\%.

Na Tabela 3 são apresentados os valores, a cada mês, do parâmetro de umidade, observando-se teores médios de 3,70\% e 2,25\% para as amêndoas tipo LW1 e tipo W4TS, respectivamente. Esse decréscimo observado no parâmetro de umidade pode estar relacionado com o processo de tostagem, pois, neste, ocorre perda de água no produto. Andrade (1984) verificou o percentual de umidade para amêndoa crua de $3,89 \%$ e para tostada de $2,29 \%$. Cavalcante (1983) obteve perdas de umidade de 6,70\% nas amêndoas cruas e $2,96 \%$ nas tostadas.

Tabela 3 - Teores de umidade nas amêndoas cruas e nas amêndoas torradas e salgadas

\begin{tabular}{c|c|c}
\hline \multirow{2}{*}{ Estocagem (mês) } & \multicolumn{2}{|c}{ Umidade (\%) } \\
\cline { 2 - 3 } & $\begin{array}{c}\text { Amêndoa crua } \\
\text { LW1 }\end{array}$ & $\begin{array}{c}\text { Amêndoa torrada } \\
\text { e salgada W4TS }\end{array}$ \\
\hline 01 & 2,80 & 2,30 \\
\hline 02 & 3,55 & 2,33 \\
\hline 03 & 3,67 & 2,13 \\
\hline 04 & 3,92 & 2,18 \\
\hline 05 & 2,92 & 2,27 \\
\hline 06 & 3,98 & 2,23 \\
\hline 07 & 4,26 & 2,23 \\
\hline 08 & 3,86 & 2,17 \\
\hline 09 & 3,64 & 2,37 \\
\hline 10 & 4,09 & 2,30 \\
\hline 11 & 3,74 & 2,37 \\
\hline 12 & 4,02 & 2,17 \\
\hline Média \pm Desvio & $\mathbf{3 , 7 0} \pm \mathbf{0 , 4 4}$ & $\mathbf{2 , 2 5} \pm \mathbf{0 , 0 8}$ \\
Padrão & &
\end{tabular}

Nota: Valores médios numa mesma linha com letras minúsculas e iguais não diferem significativamente entre si a $5 \%$ de probabilidade, segundo o Teste de Tukey.

Ainda comparando o parâmetro de umidade, Neto (2000) apresentou valores de umidade entre $3,58 \%$ a $4,20 \%$ em amostras analisadas, semelhan- tes ao encontrado na amêndoa crua. Segundo Lima (2002), a amêndoa muito úmida torna-se elástica e pouco apreciada pelo consumidor. Andrade (1984) apresentou um teor médio de umidade de $3,89 \%$ antes da tostagem e um teor de 2,29\% após esse processo, redução semelhante à encontrada em nossa análise.

Tabela 4 - Índices de peróxidos das amêndoas cruas (LW1) e das amêndoas torradas e salgadas (W4TS)

\begin{tabular}{c|c|c}
\hline \multirow{2}{*}{ Estocagem (mês) } & \multicolumn{2}{|c}{ Índices de peróxidos (mEq/Kg) } \\
\cline { 2 - 3 } & $\begin{array}{c}\text { Amêndoa crua } \\
\text { LW1 }\end{array}$ & $\begin{array}{c}\text { Amêndoa torrada } \\
\text { e salgada W4TS }\end{array}$ \\
\hline 01 & 0,33 & 0,92 \\
\hline 02 & 0,42 & 0,75 \\
\hline 03 & 0,90 & 1,50 \\
\hline 04 & 1,73 & 2,40 \\
\hline 05 & 2,10 & 3,30 \\
\hline 06 & 1,65 & 5,20 \\
\hline 07 & 0,10 & 0,54 \\
\hline 08 & 0,40 & 2,70 \\
\hline 09 & 1,66 & 1,10 \\
\hline 10 & 0,46 & 1,70 \\
\hline 11 & 0,85 & 1,80 \\
\hline 12 & 1,70 & 3,70 \\
\hline Média \pm Desvio & $\mathbf{1 , 0 2} \mathbf{b}^{\mathrm{b}} \pm \mathbf{0 , 7 0}$ & $\mathbf{2 , 1 3}$ a $\pm \mathbf{1 , 3 9}$ \\
Padrão & &
\end{tabular}

Nota: Valores médios numa mesma linha com letras minúsculas e iguais não diferem significativamente entre si a $5 \%$ de probabilidade, segundo o Teste de Tukey.

Sob o ponto de vista oxidativo, pode-se verificar na Tabela 4 que os valores obtidos foram baixos para o índice de peróxido, apresentando teores médios de $1,03 \mathrm{mEq} / \mathrm{Kg}$ para as amêndoas cruas e $2,13 \mathrm{mEq} / \mathrm{Kg}$ para as amêndoas torradas e salgadas, sendo esses resultados diferentes significativamente ao nível de 5\% de probabilidade. Esses teores se apresentaram inferiores aos observados por Andrade (1984), que verificou um teor médio de $5,98 \mathrm{mEq} / \mathrm{Kg}$ nas amêndoas cruas, e nas amêndoas tostadas com sal um valor médio de $4,59 \mathrm{mEq} / \mathrm{Kg}$. Foram inferiores, também, ao valor máximo preconizado por Brasil (2005), que é de $10 \mathrm{mEq} / \mathrm{Kg}$ para óleos e gorduras vegetais refinadas. $\mathrm{O}$ aumento desse índice durante o armazenamento evidencia o início de reações oxidativas e/ou hidrolíticas nas amostras.

$\mathrm{O}$ teor de ranço também foi observado nas amêndoas cruas e nas amêndoas torradas e salgadas 


\section{6}

pelo período de 12 meses, verificando-se que essas amêndoas apresentaram ausência de tal parâmetro. Esse fato pode estar relacionado aos baixos valores encontrados para o índice de peróxido, que indicam um produto livre ou com poucas reações entre os ácidos graxos insaturados e o oxigênio atmosférico. Também pode ser correlacionado com os percentuais de acidez titulável, por não ter apresentado liberação de ácidos graxos dos triglicerídeos pela ação das enzimas lipases, pois isso ocasionaria sabor desagradável e alterações nas propriedades funcionais das amêndoas cruas e nas amêndoas torradas e salgadas.

Em relação aos parâmetros microbiológicos analisados, os resultados encontrados para a análise de Salmonella spp., para as amêndoas cruas e para as amêndoas torradas e salgadas, durante os doze meses de armazenamento, encontraram-se dentro dos parâmetros estabelecidos pela Legislação RDC $\mathrm{n}^{\mathrm{o}}$ 12, de 02 de janeiro de 2001 (BRASIL, 2001). Esse fato demonstra que as condições de processo e sanitárias foram controladas devidamente, o que indica eficiência nas Boas Práticas de Fabricação.

Na Tabela 5 são apresentados os resultados das análises de Salmonella spp. e Coliformes a $35^{\circ}$ e $45^{\circ} \mathrm{C}$ da amêndoas cruas e torradas e salgadas.

\section{CONCLUSÕES}

Os resultados das análises físico-químicas, como índice de peróxido e acidez, não apresentaram teores altos que demonstrassem a presença de reações oxidativas ou hidrolíticas que levariam a alterações nas características organolépticas do produto.

Os teores observados para o parâmetro de umidade não apresentaram grandes variações, reduzindo a probabilidade de degradação por microorganismos ou formação de compostos potencialmente tóxicos nas amostras analisadas.

De acordo com os resultados obtidos nas análises microbiológicas para as amêndoas de castanha de caju crua LW1 e as amêndoas de castanha de caju torrada e salgada W4TS, a indústria processadora desses produtos aderiu às Boas Práticas de Fabricação e Análise de Perigos e Pontos Críticos de Controle na sua linha de produção.

Pode-se concluir ainda que, durante o período de validade (12 meses) estabelecido pela empresa fornecedora da matéria-prima, tanto as amêndoas da castanha de caju crua tipo LW1 quanto as amêndoas da castanha de caju torrada e salgada tipo W4TS não apresentaram redução em sua qualidade final
Tabela 5 - Parâmetros microbiológicos observados nas amêndoas cruas e nas amêndoas torradas e salgadas no período de 12 meses

\begin{tabular}{c|c|c|c}
\hline \multirow{2}{*}{$\begin{array}{c}\text { Parâmetros } \\
\text { Analisados }\end{array}$} & Amêndoas Cruas & $\begin{array}{c}\text { Amêndoas } \\
\text { Torradas e } \\
\text { Salgadas }\end{array}$ & $\begin{array}{c}\text { Padrão } \\
\text { (RDC no 12 - } \\
\mathbf{0 2 / 0 1 / 2 0 0 1})\end{array}$ \\
\cline { 2 - 3 } Salmonella spp. & Ausência & Ausência & Ausência \\
\hline Coliformes a $35^{\circ} \mathrm{C}$ & $<10 \mathrm{UFC} / \mathrm{g}$ & $<10 \mathrm{UFC} / \mathrm{g}$ & $103 \mathrm{UFC} / \mathrm{g}$ \\
\hline Coliformes a $45^{\circ} \mathrm{C}$ & $<10 \mathrm{UFC} / \mathrm{g}$ & $<10 \mathrm{UFC} / \mathrm{g}$ & $103 \mathrm{UFC} / \mathrm{g}$ \\
\hline
\end{tabular}

\section{REFERÊNCIAS}

A.O.A.C. ASSOCIATION OF OFFICIAL ANALYTICAL CHEMISTS. Official methods of analysis of the AOAC Internacional. 16 ed. Arlington: AOAC, 1998. v. 1-2.

ANDRADE, J. S. Aspectos da industrialização da castanha de caju (Anacardium occidentale L.). Fortaleza, 1984. 187p. Dissertação (Mestrado em Tecnologia de Alimentos), Universidade Federal

do Ceará.

Os resultados obtidos de coliformes fecais e coliformes totais tanto para a amêndoa crua LW1 como para a amêndoa torrada e salgada W4TS foram $<10 \mathrm{UFC} / \mathrm{g}$. Esses resultados refletem tanto as boas condições sanitárias dos equipamentos e utensílios utilizados na indústria, como o padrão de higiene pessoal dos funcionários e das embalagens utilizadas. Estão, portanto, de acordo com a Legislação RDC n ${ }^{\circ}$ 12, de 02 de janeiro de 2001 (BRASIL, 2001).
APHA. American Public Health Association. Compendium of methods for the microbiological examination of foods. 3 ed. Washington: APHA, 1992.

ARAUJO, M. C.; FERRAZ, A. C. O. Efeito da umidificação, tratamento térmico e deformação sobre a decorticação da castanha de caju 'CCP-76' por meio de impacto único e direcionado. Engenharia Agrícola, Jaboticabal, v. 26, n. 2, ago. 2006. Disponível em: <http://www. scielo.br/scielo.php?script $=$ sci_arttext\&pid $=$ S0100 $-69162006000200029 \& \operatorname{lng}=\mathrm{en} \& \mathrm{nrm}=\mathrm{iso}>$. Acesso em: 15 mar. 2009. Doi: 10.1590/S0100-69162006000200029. 
BARCELÓ COLL, J.; R. NICOLÁS RODRÍGUEZ, G.; SABATER GARCÍA, B. Fisiologia vegetal. Madrid, España: Editorial Pirámide, 2005. 566 p.

BRASIL. Agência Nacional de Vigilância Sanitária. Resolução RDC n. 270, de 22 de setembro de 2005. Regulamento técnico para óleos, gorduras vegetais e creme vegetal. Diário Oficial [da] República Federativa do Brasil, Brasília, 23 de setembro de 2005.

Resolução RDC n.12, de 02 de janeiro de 2001. Dispõe sobre os princípios gerais para o estabelecimento de critérios e padrões microbiológicos para alimentos. Agência Nacional de Vigilância Sanitária (ANVISA). Disponível em: <http:// www.vigilanciasanitaria.gov.br/anvisa.html>. Acesso em: 15 mar. 2009.

CAVALCANTE, J. F. M. Une contribution a l'etude de la valuer nutritive de la noix de cajou (Anacardium occidentale L.) an Bresil. Bélgica, 1983. 61p. Dissertação (Mestrado em Sciences Naturelles Appliquees), Universite Catholique de Louvain.

FIEC - FEDERAÇÃO DAS INDÚSTRIAS DO ESTADO DO CEARÁ. O desafio da cajucultura. Revista da FIEC. Fortaleza, v. 1, n. 6, novembro, 2007.

FRANÇA, F. M. C.; BEZERRA, F. F.; MIRANDA, E. Q.; SOUSA NETO, J. M. Agronegócio do caju no Ceará: cenário atual e propostas inovadoras. Fortaleza: Federação das Indústrias do Estado do Ceará, Instituto de Desenvolvimento Industrial do Ceará, 2008.

I.A.L. Métodos físicos e químicos para análise de alimentos. In: INSTITUTO ADOLFO LUTZ. Normas analíticas do Instituto Adolfo Lutz. 4. ed. São Paulo, 2004. 989p.

IBGE. Instituto Brasileiro de Geografia e Estatística. Produção municipal agricola (2008). Disponível em: <http:// www.sidra.ibge.gov.br/bda/>. Acesso em: 08 abr. 2009.

LIMA, J. R.; SOUSA, M. M. M. Influência do tipo de óleo utilizado para fritura na estabilidade de amêndoas de castanha de caju. Boletim CEPPA, Curitiba, v. 19, n. 1, p. 43 - 52, jan./dez., 2001.

LIMA, J. R. Vida de prateleira de amêndoas de castanha de caju em embalagens comerciais. Fortaleza: Embrapa Agroindústria Tropical, 2002 (Comunicado Técnico).

LIMA, J. R.; BORGES, M. F. Armazenamento de amêndoas de castanha de caju: influência da embalagem e da salga. Revista Ciência Agronômica, vol. 35, n.1, p. 104-109, jan./ jun., 2004.

MAIA, G. A; STULL, J. W. Características químicas e físicas da castanha de caju (Anacardium occidentale L.). Revista Ciência Agronômica, Fortaleza, v.7, n.1-2, p. 49- 52, dez. 1977.

MATTA, V. M.; CABRAL, L. M. C.; SILVA, L. F. M. Suco de acerola microfiltrado: avaliação da vida-de-prateleira.
Revista Ciência e Tecnologia de Alimentos, Campinas, v. 24, n. 2, June 2004 . Disponível em: <http://www. scielo.br/ scielo.php?script=sci_arttext\&pid=S0101$-20612004000200023 \& \operatorname{lng}=e n \& \mathrm{nrm}=\mathrm{iso}>$. Acesso em: 15 de mar. 2009. Doi: 10.1590/S0101-20612004000200023.

MELO, M. L. P. et al. Caracterização físico-química da amêndoa da castanha de caju (Anacardium occidentale L.) crua e tostada. Revista Ciência e Tecnologia de Alimentos [online]. 1998, vol.18, n.2, pp. 184-187. ISSN 0101-2061. Doi: 10.1590/S0101-20611998000200008.

MORETTO, E.; FETT, R. Tecnologia de óleos e gorduras vegetais na industria de alimentos. São Paulo: Livraria Varella, 1998.

NETO, R. M. S. Inspeção em indústria de beneficiamento de castanha de caju visando à implantação das boas práticas de fabricação. Fortaleza, 2000. 128p. Dissertação (Mestrado em Tecnologia de Alimentos), Universidade Federal do Ceará. Fortaleza.

QUEIROGA NETO, V. Efeito do processamento térmico sobre propriedades funcionais de proteínas de amêndoas de castanha de caju (Anacardium occidentale L.). João Pessoa, 1993. 94p. Dissertação (Mestrado em Tecnologia de Alimentos), Universidade Federal da Paraíba.

STENZEL, N. M. C.; NEVES, C. S. J. V.; MARUR, C. J.; SCHOLZ, M. B. dos S.; GOMES, J. C. Maturation curves and degreedays accumulation for fruits of 'Folha Murcha' orange trees. Scientia Agricola, v.63, n.3, p.31-36, 2006.

TEIXEIRA, A. J. Indústria de caju no Brasil. SINDICAJU (Sindicato das Indústrias de Beneficiamento de Castanha de Caju e Amêndoas Vegetais do Estado do Ceará), 2007. Disponível em: <http://www.sindicaju.org.br/site/noticia. industria.html >. Acesso em: 10 abr. 2009. 